Journal of Machine Engineering, 2021, Vol. 21, No. 4, 72-89

ISSN 1895-7595 (Print) ISSN 2391-8071 (Online)

Received: 19 September 2021 / Accepted: 01 December 2021 / Published online: 05 December 2021

surface roughness, response surface, milling method, optimization

Nguyen Huu LOC ${ }^{1,2 *}$

Trinh Quoc HUNG ${ }^{1,2}$

\title{
OPTIMIZATION OF CUTTING PARAMETERS ON SURFACE ROUGHNESS AND PRODUCTIVITY WHEN MILLING WOOD MATERIALS
}

\begin{abstract}
The quality of the machined surface is one of the most important criteria when products are processed. For different materials, there are differentially fitting processing technologies and cutting modes to ensure that the parts have surface roughness in the allowed value range. In this paper, the research on surface roughness of machining tropical wood by milling method is presented. It is necessary to establish and solve the optimal problems with such aims as the highest surface quality, minimum cutting power and the highest productivity in the optimal cutting mode. Using a great amount of experimental planning and many constrained nonlinear optimization problem solving methods, the authors built a process and solved the problem to determine the optimal cutting parameters such as feed per tooth $S_{z}$, tool tip radius $\rho$, depth of cut $h$, etc. that satisfy the above object. Research object is tropical wood chukrasia and this is the database to design woodworking machines by milling method and choose a reasonable working mode when processing on CNC machines.
\end{abstract}

\section{INTRODUCTION}

The surface quality of solid wood products is one of the important properties which have a direct influence on continuous manufacturing processes such as finishing and the durability of glue line and joints. In the research of Kilic [1] the surface roughness of wood can be affected by various factors such as annual ring variation, wood density, cell structure or latewood/earlywood ratio.

The studies that have been carried out abroad in this field are now in abundance. Many authors have studied the defects, methods and errors frequently caused by the structure of the wood and the influence on the processing and manufacturing, so the process can be optimized through adjusting the machining parameters. In the paper of Wilkowski [2] a great deal of research in this direction currently focuses on temperate wood - low density common wood $\left(<450 \mathrm{~kg} / \mathrm{m}^{3}\right)$. However, in the studies of Pereira [3], the optimization problem has not been solved comprehensively.

\footnotetext{
${ }^{1}$ Faculty of Mechanical Engineering, Ho Chi Minh city University of Technology (HCMUT), Vietnam

${ }^{2}$ VietNam National University of Ho Chi Minh City (VNUHCM), Vietnam

*E-mail: nhloc@hcmut.edu.vn https://doi.org/10.36897/jme/144426
} 
From the actual needs and typical studies such as the influence of processing parameters on the quality of processed wood surface [2, 4, 5-10], the criteria and methods that can effectively evaluate the quality of processed wood [11], or the influence of cutting tool geometry on surface roughness during machining in the research of Keturakis [12], it can be shown that there are two common targets to be achieved: the quality of the wood surface after processing and processing productivity - processing cost. Regarding the machining productivity objective, the quality of the machined surface is also included; but in terms of constraints, it is within the acceptable range.

In their paper, Dobrzynski et all [13] presents the selected results of research of the effect of the cutting tool wear on the surface quality of elements after planning. Through the studies of Wilkowski [2,4], Pereira [3], Zhong [11], Keturakis [12], it has been shown that the problems in the machining process have directly affected the machining quality, including: tool tip radius (tool wear) $\rho$, feed per tooth $S_{z}$, cutting speed $v$, and depth of cut $h$. In this paper these parameters will be set up and built into a problem process with the objective function of cutting power or cutting mode on the basis of optimization constraint functions, from which there is a basis for experimentation, evaluation and comparison with the work before. In addition, there are no adequate studies on tropical woods and in this paper, the research object is tropical wood chukrasia.

\section{THEORETICAL BACKGROUND OF MILLING}

To be able to process wood, there are now many different methods depending on the needs of the shape of the finished products. One of the most common methods is milling, specifically the four-side planer or CNC router as shown in the schematic diagram in Fig. 1.

In the diagram in Fig. 1, the milling region is divided into 3 parts: processed surface, cutting surface and processable surface. The parameters of milling process (Fig. 1) include: tool radius $R=D / 2(\mathrm{~mm})$, depth of cut h $(\mathrm{mm})$, width of workpiece $b(\mathrm{~mm})$, feed per tooth $S_{z}$ (mm/tooth), number of knives z (tooth), spindle speed $n(\mathrm{rpm})$, feeding speed $u(\mathrm{~m} / \mathrm{min})$.

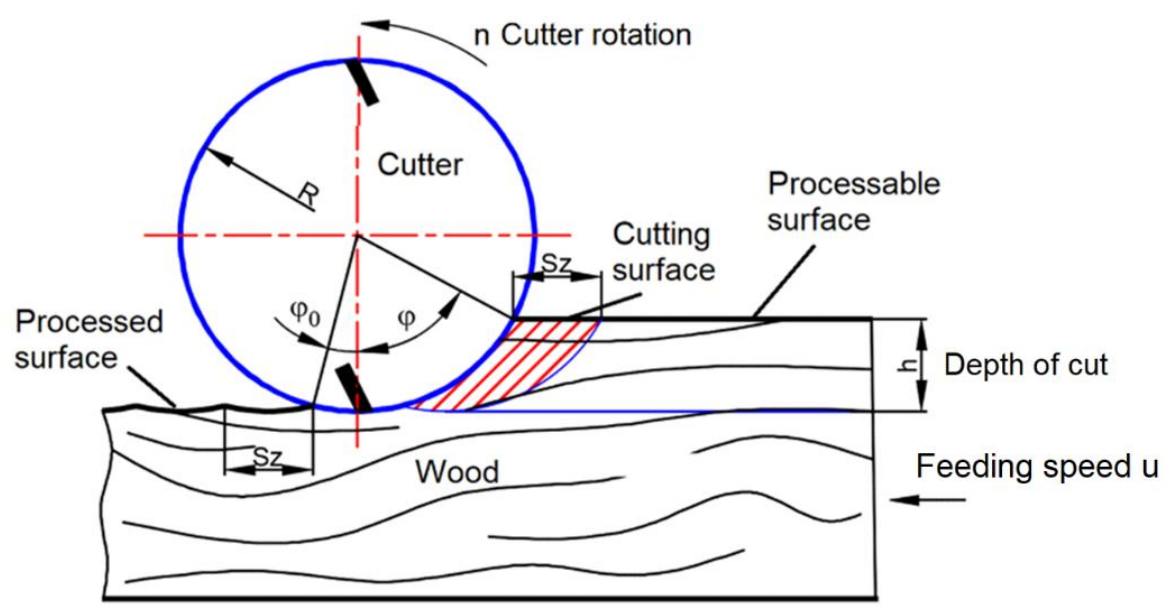

Fig. 1. The wood milling scheme 
To evaluate the quality of the wood surface after processing, specifically the surface roughness here, the geometrical factors of the roughness are used as the indicator. It is determined within the standard length and calculated against the average of the surface profile. The assessment of roughness is used according to 2 criteria: the arithmetical mean roughness $R_{a}$ and the ten-point average roughness $R_{z}$. In this paper, the selected parameter for surface roughness evaluation is the $R_{z}$. Because the wood surface when milled is too rough, this measurement will be more accurate than the $R_{a}$ criterion. The roughness when machining by milling: rough $-R_{z}=100 \ldots 315 \mu \mathrm{m}$, semi-finished $-R_{z}=30 \ldots 100 \mu \mathrm{m}$, fine-finished $-R_{z}$ $=16 \ldots 30 \mu \mathrm{m}$. In this study, we use the semi-finished milling method and limit the roughness $\mathrm{R}_{\mathrm{z}} \leq 70 \mu \mathrm{m}$, corresponding to raw sanding of Gökay et all [14]. Sandak et all [15] stated that all wood surface measurements can be performed in industrial conditions using either in-line, on-line or off-line strategies.

Optimal cutting modes are selected to reduce cutting power loss, to improve machining productivity, tool life and wear resistance, accuracy and machined surface quality. Therefore, it is necessary to have theoretical studies on wood cutting, cutting modes, the influence of factors on cutting power, surface roughness and tool survive life.

The cutting parameters of the wood planning process have been thoroughly studied, while the profile of the shaping milling process has not been fully studied.

\subsection{CHIP THICKNESS WHEN MILLING WOOD WITH INCLINED MILLING BLADE}

Among the parameters that have the greatest influence on the cutting mode, the most important are those related to the cutting layer of material, specifically the chip thickness. The chip thickness is the most important factor in the milling process. This factor determines the chip forming process characteristics and affects the cutting power, surface roughness, as well as machining productivity.

The wood milling process with the cutter blade inclined profile $\psi$ works more quietly than planer milling. It can be explained as follows: The instantaneous cross-sectional area of the chip changes because the chip width and the chip thickness change instantaneously during cutting. The chip width changes from 0 at the start of cutting to the maximum value, holds constant, and then gradually decreases from the maximum value to 0 .

The problem of determining the chip thickness when milling wood has been studied by many researchers Fisher [16], Rozenblit [17], Salomon [18], etc.

According to Fisher [16], the chip thickness is determined by the following formula:

$$
a=S_{z} \sin \varphi
$$

According to Rozenblit [17], the chip thickness is determined by the following formula:

$$
a=S_{z} \sin \left(\varphi+\frac{\pi S_{z} \cos \varphi}{\pi D \pm z \cos \varphi}\right) \frac{\pi D}{\pi D \pm S_{z} z \cos \varphi}
$$

where: $a$ is the chip thickness; $S_{z}$ is the feed per one tooth; $z$ is the number of knives; $D$ is the milling cutter diameter; $\varphi$ is the angle of rotation of the cutting tool. " + " sign is for reverse (conventional) milling, "-" sign for forward (climb) milling. Martelotti [19] gives a more precise formula for chip thickness $a_{\max }$ : 


$$
a_{\text {max }}=\frac{D S_{Z}\left\{\frac{D}{2}+\frac{2}{3}\left[\frac{v}{2 \pi n} \cos ^{-1}\left(\frac{D-2 h}{D}\right)-S_{Z}\right]\right\} \sin \left\{\frac{180\left[\frac{D}{2}+\frac{v}{2 \pi n} \cos ^{-1}\left(\frac{D-2 h}{D}\right)-S_{Z}\right]}{\pi\left(\frac{v}{2 \pi n}+\frac{D}{2}-\frac{2}{3} S_{Z}\right)}\right\}}{2\left\{\left(\frac{v}{2 \pi n}\right)^{2}+\left(\frac{D}{2}\right)^{2}+\frac{v D}{2 \pi n}\right\} \cos \left\{\frac{\frac{180}{\pi}\left[\left(\frac{v}{2 \pi n}+\frac{D}{2}\right) \cos ^{-1}\left(\frac{D-2 h}{D}\right)-S_{Z}\right]}{\left(\frac{v}{2 \pi n}+\frac{D}{2}-\frac{2}{3} S_{Z}\right)}\right\}}
$$

In practice, the milling profiles have many different complex shapes. Therefore, we can interpolate them by straight lines with different angles of inclination of the cutter $\psi_{i}$. Then the average value of the thickness of the workpiece is determined by the formula:

$$
a_{m}=S_{z} \sqrt{\frac{h_{m}}{D_{m}}}
$$

where: $h_{m}, D_{m}$ are mean values of cutting depth and tool diameter.

When wood is milled with a cutting blade with an inclined profile $\psi$ and a positive front angle, the milling blade with the largest diameter will cut the chip first, then the smaller diameter tip positions. The maximum chip width is obtained when the position of the tool with the smallest diameter participates in the chip making process. The chip formation process is divided into 3 stages of I, II and III as shown in Fig. 2.

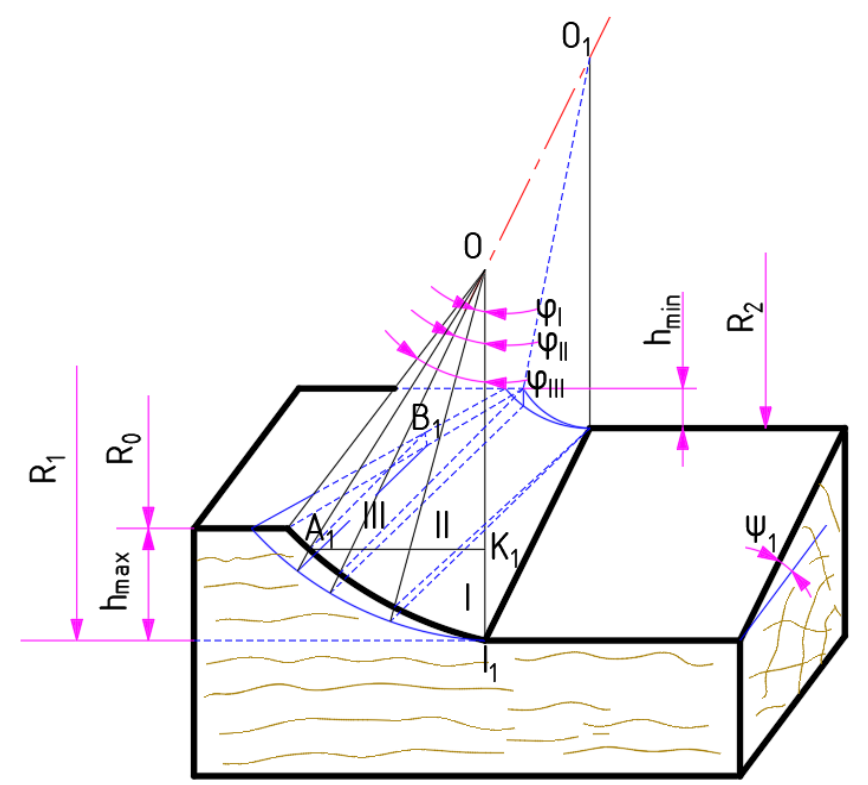

Fig. 2. Chip formation when milling wood with inclined milling blade $\psi$

Figure 3 is used to determine the chip thickness and cross-sectional area of the chip when milling wood with a cutting blade with an inclined profile $\psi$. Then AI is the chip thickness in the radial direction $a_{r}$ and the average chip thickness is determined by Nguyen [12] with the formula:

$$
a_{r}=A I=S_{z} \sin \varphi
$$

The chip thickness a is determined in the plane AFL perpendicular to the blade AB, and the segment AL is determined by the formula (Fig. 3):

$$
a=a_{r} \cdot \cos \varepsilon=S_{z} \cdot \sin \varphi \cdot \cos \varepsilon
$$


When wood is milled with a milling cutter with an inclination angle $\psi$, the movement of the milling cutter cutting edge creates the hyperboloid one sheet. The equation for this surfaces is:

$$
F(x, y, z)=\frac{y^{2}}{R^{2} \sin ^{2} \gamma}+\frac{z^{2}}{R^{2} \sin ^{2} \gamma}-\frac{(R \cos \gamma-x \tan \psi)^{2}}{R^{2} \sin ^{2} \gamma}-1=0
$$

The parametric equation of the normal to the hyperboloid one sheet at point $A(0, R, 0)$ has the form:

$$
\mathrm{Z}=a_{1} \cdot t ; \quad y-R=b_{1} \cdot t ; \quad x=c_{1} \cdot t
$$

The coefficients $a_{1}, b_{1}, c_{1}$ are determined by the equation:

$$
\left\{\begin{array}{l}
\mathrm{a}_{1}=\frac{\partial \mathrm{F}(0, \mathrm{R}, 0)}{\partial \mathrm{x}}=0 \\
\mathrm{~b}_{1}=\frac{\partial \mathrm{F}(0, \mathrm{R}, 0)}{\partial \mathrm{y}}=\frac{2}{\mathrm{R} \sin ^{2} \gamma} \\
\mathrm{c}_{1}=\frac{\partial \mathrm{F}(0, \mathrm{R}, 0)}{\partial \mathrm{z}}=\frac{2 \tan \psi \cos \gamma}{\mathrm{R} \sin ^{2} \gamma}
\end{array}\right.
$$

The parametric equation of the normal to the hyperboloid one sheet at point $A$ is:

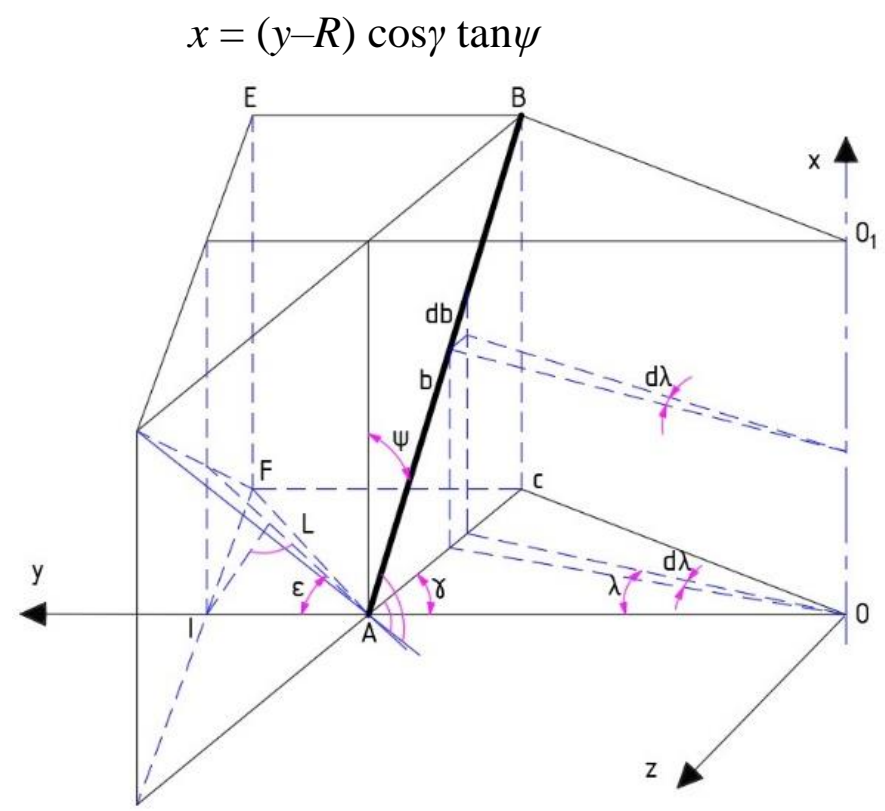

Fig 3. Geometry of the cutter and scheme determination of chip thickness

The normal of the hyperboloid of one sheet is in the coordinate plane $z O y$. An angle $\varepsilon$ between line segment AI and the normal of the hyperboloid of one sheet $\mathrm{n}$ is determined by the formula:

$$
\tan \varepsilon=\cos \gamma \cdot \tan \psi
$$

When milling wood with a curved profile cutter, the chip thickness at position $\mathrm{i}$ is determined by the formula: 


$$
a=S_{z} \cdot \sin \varphi \cdot \cos \varepsilon_{i}
$$

where $\tan \varepsilon_{i}=\cos \gamma_{i} \cdot \tan \psi_{i}$ and $\psi_{i}$ is the angle of inclination of the cutter profile, which is determined at position $i$ on the tip of the cutter blade; $\gamma_{i}$ is front angle of the cutter at $i$.

\subsection{SURFACE WAVINESS HEIGHT AND CUTTING LENGTH L}

The path of the milling tool during cutting in Fig. 1 is a cycloidal line. This equation of the cycloid line is $[5,20]$ :

$$
\left\{\begin{array}{l}
x=R \sin \varphi \pm \frac{s_{z}}{\varphi_{z}} \varphi \\
y=R(1-\cos \varphi)
\end{array}\right.
$$

where $\varphi_{z}$ is the angle between the milling blades and $\varphi_{z}=2 \pi / z$. From Fig. 1, we deduce the formula:

$$
\sin \varphi_{0}=S_{z} / 2 R
$$

Since the angle $\varphi_{0}$ is small, we get an approximate $\varphi_{0}=S_{z} / 2 R$.

The arc cutting length is determined by the following formula:

$$
l=R\left(1+\frac{S_{Z}^{2}}{2 R^{2} \varphi_{z}^{2}}\right)\left(\varphi+\varphi_{0}\right)+ \pm \frac{S_{Z}}{\varphi_{z}}\left(\sin \varphi+\sin \varphi_{0}\right)
$$

because $\frac{S_{z}{ }^{2}}{R^{2} \varphi_{z}{ }^{2}} \pm 2 \frac{S_{z}}{R \varphi_{z}} \cos \varphi, \varphi$ and $\varphi_{0}$ are so small, we obtain an approximate estimate for arc cutting length as follows:

$$
l=\left(R\left(1+\frac{S_{Z}^{2}}{2 R^{2} \varphi_{z}^{2}}\right) \pm \frac{S_{Z}}{\varphi_{z}}\right)+\frac{\left(S_{Z}+2 \sqrt{2 h(R-h)}\right)}{2 R}
$$

In practice, the cutting arc length is determined by the following approximate formula:

$$
l=\sqrt{h D}
$$

The surface waviness height of the processed surface is $H_{\max }$, determined by the following formula:

$$
\left\{\begin{array}{l}
\frac{S_{z}}{2}=R \sin \varphi_{0} \pm \frac{S_{z}}{\varphi_{z}} \varphi_{0} \\
H_{\max }=\left(1-\cos \varphi_{0}\right)
\end{array}\right.
$$

Since the angle $\varphi_{0}$ is small, we approximate $\varphi_{0}=\sin \varphi_{0}$. Substituting into the above system of equations, we determine the surface waviness height $H_{\max }$ :

$$
H_{\max }=\left(1-\cos \left(\frac{\pi S_{z}}{2 \pi R \pm S_{z} z}\right)\right)
$$

We use the formula of cutting length $L(\mathrm{~m})$ :

$$
L=l \frac{l_{w}}{S_{z}}
$$

where $l_{w}$ is the experimental length of wood samples, (m). 


\section{MATERIALS AND METHODS}

\subsection{DESIGN OPTIMIZATION PROBLEM}

To solve a constrained nonlinear optimization problem in industry, there are many methods, such as the following: quadratic programming algorithm [21], convex programming method [22], penalty function method [23], Lagrange polynomial method [24], Kuhn-Tucker conditions [25], hill climbing algorithm, artificial neural networks [26], genetic algorithm, particle swarm [27, 28]. In mathematical optimization, the Kuhn-Tucker conditions are first derivative tests for a solution in nonlinear programming to be optimal, provided that some regularity conditions are satisfied. In this paper, among the constraints and objective functions of the optimization problems are the quadratic regression equations obtained from experiments. Therefore, if we use the Kuhn-Tucker conditions, then according to the partial derivative results, we get a system of first or second order equations and solve them easily. Initially, the constrained optimization problem is presented as follows:

Determine $\mathbf{X}=\left[\begin{array}{c}x_{1} \\ x_{2} \\ \vdots \\ x_{n}\end{array}\right]$ let $\mathrm{f}(\mathbf{X})$ reach the minimum value.

Constraints are:

- $h_{i}(\mathbf{X}) \leq 0$ with $i=1,2, \ldots, n_{i}$;

- $l_{j}(\mathbf{X})=0$ with $j=1,2, \ldots, n_{j}$.

We replace the constrained problem according to the Kuhn-Tucker conditions with the unconstrained optimization problem as follows:

$$
K(\mathbf{X}, u, v)=f(\mathbf{X})+\sum_{i=1}^{n_{i}} u_{\mathrm{i}} h_{i}(\mathbf{X})+\sum_{j=1}^{n_{j}} v_{j} l_{j}(\mathbf{X})=0
$$

Taking partial derivatives with respect to $d_{i}, u_{j}, v_{k}$, we have a system of equations:

$$
\left\{\begin{array}{l}
\frac{\partial K(\mathbf{X}, u, v)}{\partial \mathbf{X}}=0 \\
\frac{\partial K(\mathbf{X}, u, v)}{\partial u_{i}}=0 \\
\frac{\partial K(\mathbf{X}, u, v)}{\partial v_{j}}=0
\end{array}\right.
$$

From the initial database results, we proceed to build an optimization problem with the objective function being the smallest cutting power $P$ or the highest machining productivity, but at the same time having to satisfy some constraint functions:

- Cutting power must be less than required power: $P \leq P_{\text {req, }}$

- Surface limits are created by cutting method:

$$
2 S_{z}^{2}-k \rho D 10^{-3} \geq 0
$$


- The value range of tool tip radius: $4 \mu \mathrm{m} \leq \rho \leq 43 \mu \mathrm{m}$,

- Limited range of surface roughness: $R_{z} \leq 70 \mu \mathrm{m}$.

Surface limit constraint $2 S_{z}{ }^{2}-k \cdot \rho \cdot D \cdot 10^{-3} \geq 0$ only ensures that during the cutting process there will be no tool slip on the surface, but does affect the surface roughness; so in the following cases, it can be overlooked.

After having the experimental planning value of $R_{z}$, the design of the problem of surface quality and machining productivity according to Kuhn-Tucker conditions is as follows:

Problem 1: Minimum cutting power $P$ and roughness constraint $R_{z} \leq 70 \mu \mathrm{m}$.

Variable: feed per tooth $S_{z}(\mathrm{~mm})$, tool tip radius $\rho(\mu \mathrm{m})$, depth of cut $h(\mathrm{~mm})$.

Objective function: Minimum cutting power $P$.

Constraints are:

- Limited range of roughness: $R_{z} \leq 70 \mu \mathrm{m}$,

- The value range of tool tip radius: $4 \mu \mathrm{m} \leq \rho \leq 43 \mu \mathrm{m}$.

Cutting power of chukrasia wood [29]:

$$
\begin{aligned}
P= & \mathrm{S}_{\mathrm{z}} \cdot\left(70.28-50.24 \cdot S_{z}-21.29 \cdot h+2.131 \cdot \rho+13.57 \cdot S_{z}^{2}+3.39 \cdot h^{2}+\right. \\
& \left.+0.016 \cdot \rho^{2}+5.366 \cdot S_{z} \cdot h-0.6752 S z \cdot \rho-0.411 \cdot h \cdot \rho\right) / 60000
\end{aligned}
$$

Problem 2: The highest machining productivity with roughness constraint $R_{z} \leq 70 \mu \mathrm{m}$ and cutting power $P \leq P_{\text {req. }}$.

In the problem of machining productivity, the increase in productivity corresponds to an increase in the volume of material removal, which is closely related to the speed of inserting the workpiece into the machine, so:

- Variable: feed per tooth $S_{z}(\mathrm{~mm})$, tool tip radius $\rho(\mu \mathrm{m})$,

- Objective function: Feeding speed $u=S_{z} \cdot n \cdot z / 1000$ reaches the maximum value. Constraints are:

- Cutting power: $P \leq P_{\max }=P_{\text {req }}$ or $P-P_{\text {req }} \leq 0$,

- Limited range of roughness: $R_{z} \leq 70 \mu \mathrm{m}$,

- The value range of tool tip radius: $4 \mu \mathrm{m} \leq \rho \leq 43 \mu \mathrm{m}$.

Problem 3: The lowest processing cost with constraint $R_{z} \leq 70 \mu \mathrm{m}$, low power loss and high machining productivity.

The processing cost $K$ is determined as follows [30]:

$$
K=K_{M L} \tau_{0}+K_{d} \frac{\tau_{c}}{T}
$$

where: $K_{M L}$ is machine depreciation coefficient and cost for operative employees; $\tau_{0}$ is basic cutting time; $K_{d}$ is costs associated with one tool change; $\tau_{c} / T$ is the number of knife changes; $T$ is tool service life.

Objective function: Basic cutting time reaches minimum value:

$$
\tau_{0}=\frac{L}{u} \rightarrow \text { minimum }
$$

where $\tau_{0}$ is basic cutting time when milling ( $\left.\mathrm{min}\right) ; u$ is feeding speed $(\mathrm{m} / \mathrm{min}) u=n \cdot z \cdot S_{z} / 1000$; $L$ is machining length $(\mathrm{m})$.

Machining length $L$ is calculated by the formula of tool tip radius $\rho$ : 


$$
\rho=\rho_{0}+\Delta \rho
$$

$\rho=4.96 \cdot \mathrm{L}^{0.43}+4$ for alloy steel $(8 \mathrm{Cr} 6 \mathrm{NiWT})$

$\rho=2.83 \cdot \mathrm{L}^{0.41}+4$ for carbide WCCO6

Assuming we use an alloy steel cutting tool, then the objective function is the basic cutting time when milling $\tau_{0}$ at the tooltip radius $\rho$ is:

$$
\tau_{0}=\frac{0.43 \sqrt{\frac{\rho-\rho_{0}}{4.96}}}{n \cdot z \cdot S_{Z}}
$$

Variable: feed per tool $S_{z}(\mathrm{~mm})$, tool tip radius $\rho(\mu \mathrm{m})$

Constraints are:

- Cutting power $P$ lowercase

- High productivity (high feeding speed $u$ )

- Limited range of roughness $R_{z} \leq 70 \mu \mathrm{m}$

- The value of tool tip radius $4 \mu \mathrm{m} \leq \rho \leq 43 \mu \mathrm{m}$

\subsection{RESPONSE SURFACE DESIGNS METHODS AND MATERIALS}

Based on the experimental results of 3 values: coefficient $k$, power $P$ and roughness $R_{z}$, we design the optimization problem. Power $P$ is determined by Formula (24), depending on the following factors: feed per tooth $S_{z}(\mathrm{~mm})$, depth of cut $h(\mathrm{~mm})$, tool tip radius $\rho(\mu \mathrm{m})$. The coefficient $k$ determines the chip forming region [20], depending on the factors: $S_{z}(\mathrm{~mm})$, $\rho(\mu \mathrm{m})$, and cutting diameter $D(\mathrm{~mm})$.

Since all response surface designs, including $3^{\mathrm{k}}$, Box-Behnken, $D$-optimal, and Central Composite Design (FCCCD, Box-Wilson, Box-Hunter), deliver models with main effects, two-factor interactions, and quadratic terms, other criteria which the models can be fitted must be considered in deciding which design should be used for a response surface experiment. There are three criteria employed to compare the design families, i.e. the number of observations in the design and the number of error degrees of freedom, the number of levels required for each design variable and the safety of the highest and lowest variable levels. The accuracy of the mathematical model is determined by the variance of the regression equation coefficients and the experimental results. Thus, from the experimental point of view, the best planning is the one that allows obtaining a regression model with the smallest value of variance [32]. In this paper, we use the FCCCD method for experimental study of surface roughness $R_{z}$ because we perform less than $\mathrm{N}$ experiments and each factor uses only 3 levels of values and the obtained regression equation ensures accuracy and compatibility. This method has been used by Nguyen [29, 31, 32] and Hazir [33].

After examining previous studies, the surface roughness $R_{z}$ depends mainly on the following factors: feed per tooth $S_{z}(\mathrm{~mm})$, tool tip radius $\rho(\mu \mathrm{m})$, rake angle $\gamma\left({ }^{\circ}\right)$, grain deviation angle $\psi_{C}\left({ }^{\circ}\right)$, blade inclination angle $\psi\left({ }^{\circ}\right)$. In addition to grain deviation angle $\psi_{C}$ for the studying the longitudinal (parallel) to tangential (radial) milling of wood grain, the value of the angle $\psi$ of inclination is given in the research with the purpose to study the process of planar, angular and profile milling wood materials. The experiment was 
performed on milling machine and a H350 double-sided planer and the subject machining was chukrasia wood. The cutting directions during machining in the paper is conventional milling (Fig. 1).

With 5 factors, the required numbers $N=44$ of experimental points were determined (Table 3 ) for FCCCD $\left(2^{5}=32\right.$ corner points, $2.5=10$ axial points and 2 center points). In each experiment we have to repeat $n$ times. To determine the number of replicates for each experiment, we conducted separate experiments of machining surface roughness and $n=8$ being determined. The mechanical properties of machining tropical woods are for experiment materials - chukrasia (Table 1):

Table 1. Mechanical properties of chukrasia wood

\begin{tabular}{|c|c|c|c|c|}
\hline \multicolumn{1}{|c|}{ Material } & $\begin{array}{c}\text { Density } \\
\left(\mathrm{kg} / \mathrm{m}^{3}\right)\end{array}$ & $\begin{array}{c}\text { Tensile strength } \\
\sigma_{\mathrm{T}}(\mathrm{MPa})\end{array}$ & $\begin{array}{c}\text { Compressive strength } \\
\sigma_{\mathrm{c}}(\mathrm{MPa})\end{array}$ & $\begin{array}{c}\text { Flexion strength } \\
\sigma_{\mathrm{F}}(\mathrm{MPa})\end{array}$ \\
\hline $\begin{array}{l}\text { Chukrasia tabularis var } \\
\text { attopenesis }\end{array}$ & $600-810$ & 2.8 & 44.7 & 118 \\
\hline
\end{tabular}

In the wood milling principle diagram shown in Fig. 1, we assume the width of workpiece $b=40 \mathrm{~mm}$, the milling cutter diameter $\mathrm{D}=2 \mathrm{R}=180 \mathrm{~mm}$, the depth of cut $\mathrm{h}=1 \ldots 3 \mathrm{~mm}$, the number of knives $z=6$ (Fig. 4). From these data, we can calculate spindle speed $n$, cutting speed $\mathrm{v}$ and cutting power $P$.

a)

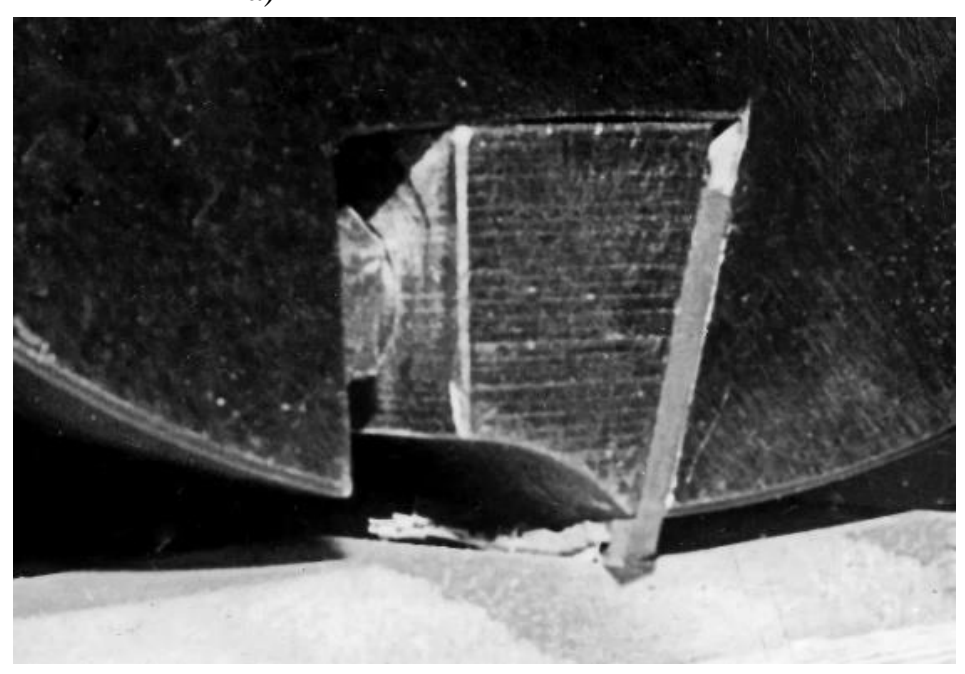

b)

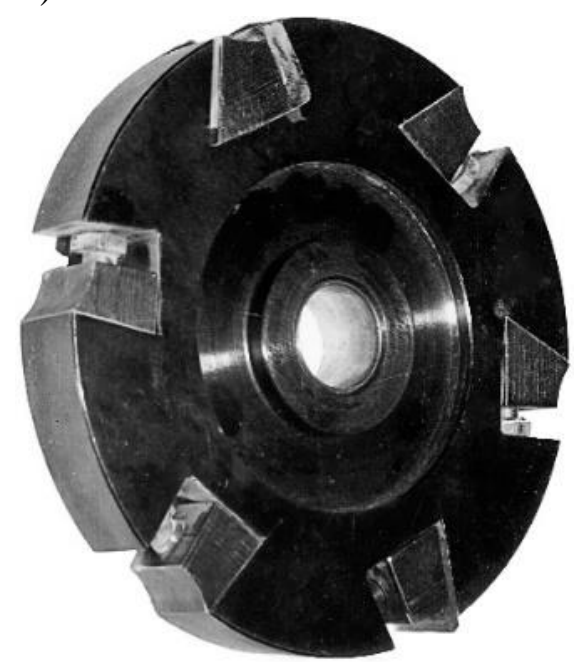

Fig. 4. Cutting process (a) and milling cutter (b)

The experiment was conducted with the spindle speed $n=6000 \mathrm{rpm}$, peripheral velocity $v=52 \mathrm{~m} / \mathrm{s}$ and $P=P_{\text {motor }}=15 \mathrm{~kW}$, and the cutter material is $8 \mathrm{Cr} 6 \mathrm{NiWT}$ steel, hardness after annealing $\mathrm{HB} \cdot 10^{-1}=241 \mathrm{MPa}$.

\begin{tabular}{|c|c|c|c|c|c|c|c|c|c|c|}
\hline $\mathrm{C}$ & $\mathrm{Si}$ & $\mathrm{Mn}$ & $\mathrm{Ni}$ & $\mathrm{S}$ & $\mathrm{P}$ & $\mathrm{Cr}$ & $\mathrm{V}$ & $\mathrm{Ti}$ & $\mathrm{Cu}$ & $\mathrm{Fe}$ \\
\hline $0.8-0.9$ & $0.1-0.4$ & $0.15-0.45$ & $0.9-1.3$ & $\leq 0.03$ & $\leq 0.03$ & $5-6$ & $0.3-0.5$ & $0.05-0.15$ & $\leq 0.3$ & Remaining \\
\hline
\end{tabular}




\section{RESULTS AND THEIR ANALYSIS}

\subsection{THE REGRESSION EQUATION OF SURFACE ROUGHNESS}

For the surface roughness $\mathrm{R}_{\mathrm{z}}$ value, it is planned according to the level and value of the factors table (Table 2), and the experimental results are shown in Table 3.

Table 2. Level and value of factors

\begin{tabular}{|c|c|c|c|c|c|}
\hline \multirow{2}{*}{ Factor } & \multicolumn{4}{|c|}{ Value level } & \multirow{2}{*}{ Interval } \\
\hline & Code & Low -1 & Medium 0 & High +1 & \\
\hline Feed per tooth $S_{z}, \mathrm{~mm}$ & $\mathrm{x}_{1}$ & 0.39 & 0.96 & 1.53 & 0.57 \\
\hline Tool tip radius $\rho, \mu \mathrm{m}$ & $\mathrm{x}_{2}$ & 4 & 23.5 & 43 & 19.5 \\
\hline Rake angle $\gamma$,degree & $\mathrm{x}_{3}$ & 12 & 24 & 36 & 12 \\
\hline Grain deviation angle $\psi_{C}$, degree & $\mathrm{X}_{4}$ & 0 & 45 & 90 & 45 \\
\hline Blade inclination angle $\psi$, degree & $\mathrm{X}_{5}$ & 0 & 45 & 90 & 45 \\
\hline
\end{tabular}

The profilometer (Mitutoyo SJ-301) is used to measure wood surface roughness $R_{z}$ after machining (Fig. 5).

Using Minitab software to process the experimental results and analyzing the variance of the regression equation, we finally get the regression equation $R_{z}$ as follows:

$$
\begin{aligned}
& R_{\mathrm{zmax}}=122.38-92.9 S_{Z}-0.59 \rho-0.76 \gamma-1.163 \psi_{C}-1.9513 \psi+34.64 S_{Z}{ }^{2}+ \\
& 0.00246 \rho^{2}-0,0022 \gamma^{2}+0.009718 \psi_{C}{ }^{2}+0.011205 \psi^{2}+0.5716 S_{Z} \rho+0.0286 S_{Z} \gamma+ \\
& 1.3438 S_{Z} \psi_{C}+1.0228 S_{Z} \psi+0.01632 \rho \gamma+0.007021 \rho \psi_{C}-0.004931 \rho \psi- \\
& 0.006847 \gamma \psi_{C}+0.023359 \gamma \psi-0.000661 \psi_{C} \psi
\end{aligned}
$$

In the case of 2 or 4 -sided planer along wood grain with a flat profile (longitudinal milling) $\psi_{C}=\psi=0$, we have the following formula for determining surface roughness:

$$
\begin{aligned}
& R_{\operatorname{zmax}}=122.38-92.9 S_{Z}-0.59 \rho-0.76 \gamma+34.64 S_{Z}{ }^{2}+0.00246 \rho^{2}-0,0022 \gamma^{2}+ \\
& 0.5716 S_{Z} \rho+0.0286 S_{Z} \gamma+0.01632 \rho \gamma
\end{aligned}
$$

a)

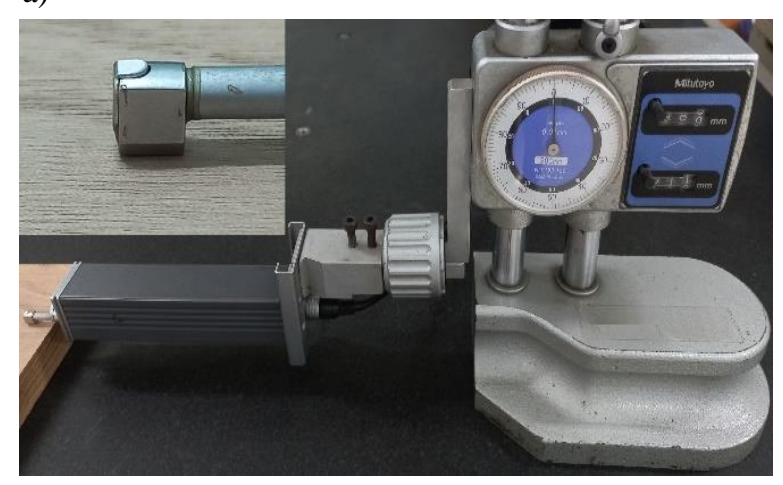

b)

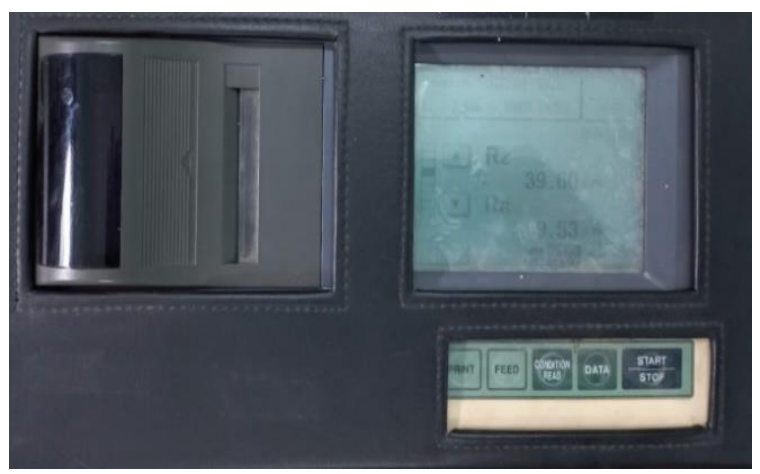

Fig. 5. Profilometer for measurement of surface roughness (a) and indicator (b) 
Table 3. Design matrix and experimental results

\begin{tabular}{|c|c|c|c|c|c|c|c|c|c|c|c|c|c|c|}
\hline \multirow[t]{2}{*}{$\mathrm{N}$} & \multicolumn{5}{|c|}{ Factor } & \multicolumn{8}{|c|}{ Experimental results } & \multirow{2}{*}{$\begin{array}{c}\text { Regression } \\
R_{z} \\
\end{array}$} \\
\hline & $S_{z}$ & $\rho$ & $\gamma$ & $\psi_{C}$ & $\psi$ & $R_{z I}$ & $R_{z 2}$ & $R_{z 3}$ & $R_{z 4}$ & $R_{z 5}$ & $R_{z 6}$ & $R_{z 7}$ & $R_{z 8}$ & \\
\hline 1 & -1 & -1 & -1 & -1 & -1 & 73.1 & 74.9 & 76.8 & 82.1 & 78.2 & 77.3 & 77.7 & 73.5 & 81.462 \\
\hline 2 & +1 & -1 & -1 & -1 & -1 & 61.5 & 60.5 & 63.4 & 62.1 & 62.4 & 67.4 & 57.4 & 60.5 & 54.359 \\
\hline 3 & -1 & +1 & -1 & -1 & -1 & 78.2 & 77.3 & 77.7 & 74.9 & 73.5 & 77.7 & 84.1 & 72.7 & 79.277 \\
\hline 4 & +1 & +1 & -1 & -1 & -1 & 70.1 & 77.6 & 80.9 & 76.7 & 74.3 & 80.9 & 73.4 & 67.7 & 77.589 \\
\hline 5 & -1 & -1 & +1 & -1 & -1 & 53.1 & 58.8 & 58.8 & 62.1 & 60.7 & 59.7 & 58.3 & 54.1 & 62.520 \\
\hline 6 & +1 & -1 & +1 & -1 & -1 & 41.1 & 35.4 & 39.6 & 39.1 & 50.1 & 38.2 & 36.8 & 40.1 & 36.200 \\
\hline 7 & -1 & +1 & +1 & -1 & -1 & 70.6 & 74.4 & 73.9 & 75.3 & 68.7 & 73.9 & 71.1 & 74.8 & 75.609 \\
\hline 8 & +1 & +1 & +1 & -1 & -1 & 71.1 & 75.7 & 74.8 & 76.7 & 78.1 & 84.8 & 64.3 & 72.4 & 74.703 \\
\hline 9 & -1 & -1 & -1 & +1 & -1 & 96.6 & 101.3 & 100.4 & 87.7 & 89.6 & 91.9 & 105.2 & 99.4 & 97.804 \\
\hline 10 & +1 & -1 & -1 & +1 & -1 & 193.9 & 206.6 & 189.1 & 199.6 & 211.3 & 216.9 & 202.8 & 211.3 & 208.578 \\
\hline 11 & -1 & +1 & -1 & +1 & -1 & 131.7 & 124.6 & 119.9 & 123.2 & 119.5 & 126.5 & 123.7 & 120.5 & 120.262 \\
\hline 12 & +1 & +1 & -1 & +1 & -1 & 254.6 & 268.9 & 246.7 & 258.9 & 256.1 & 259.3 & 252.8 & 249.9 & 256.450 \\
\hline 13 & -1 & -1 & +1 & +1 & -1 & 56.7 & 65.1 & 67.9 & 68.9 & 73.1 & 67.5 & 76.4 & 65.6 & 64.073 \\
\hline 14 & +1 & -1 & +1 & +1 & -1 & 157.8 & 164.3 & 187.1 & 177.7 & 180.9 & 169.1 & 167.2 & 175.2 & 175.630 \\
\hline 15 & -1 & +1 & +1 & +1 & -1 & 104.5 & 103.9 & 115.9 & 102.2 & 107.8 & 108.7 & 104.4 & 104.5 & 101.804 \\
\hline 16 & +1 & +1 & +1 & +1 & -1 & 225.5 & 245.1 & 241.6 & 236.9 & 239.2 & 238.8 & 234.6 & 236.5 & 238.775 \\
\hline 17 & -1 & -1 & -1 & -1 & +1 & 51.1 & 52.4 & 60.4 & 63.7 & 54.8 & 53.4 & 63.7 & 53.4 & 55.955 \\
\hline 18 & +1 & -1 & -1 & -1 & +1 & 111.1 & 129.3 & 131.2 & 120.1 & 122.7 & 131.2 & 119.3 & 121.8 & 133.792 \\
\hline 19 & -1 & +1 & -1 & -1 & +1 & 36.7 & 30.9 & 45.1 & 49.5 & 42.8 & 37.1 & 39.5 & 48.4 & 36.463 \\
\hline 20 & +1 & +1 & -1 & -1 & +1 & 150.1 & 143.3 & 145.8 & 128.6 & 149.1 & 144.1 & 128.2 & 142.4 & 139.714 \\
\hline 21 & -1 & -1 & +1 & -1 & +1 & 87.1 & 99.2 & 90.8 & 96.4 & 94.5 & 88.9 & 95.9 & 95.9 & 87.468 \\
\hline 22 & +1 & -1 & +1 & -1 & +1 & 161.2 & 163.7 & 171.4 & 156.2 & 157.8 & 170.5 & 168.8 & 162.1 & 166.088 \\
\hline 23 & -1 & +1 & +1 & -1 & +1 & 71.4 & 75.3 & 90.5 & 88.1 & 86.3 & 74.5 & 90.1 & 78.7 & 83.249 \\
\hline 24 & +1 & +1 & +1 & -1 & +1 & 175.1 & 191.2 & 180.1 & 188.6 & 183.3 & 195.2 & 194.3 & 196.1 & 187.283 \\
\hline 25 & -1 & -1 & -1 & +1 & +1 & 66.4 & 76.7 & 56.4 & 76.4 & 66.4 & 66.4 & 71.3 & 59.6 & 66.946 \\
\hline 26 & +1 & -1 & -1 & +1 & +1 & 284.2 & 291.4 & 298.2 & 291.2 & 281.4 & 301.2 & 287.3 & 299.3 & 282.659 \\
\hline 27 & -1 & +1 & -1 & +1 & +1 & 58.9 & 61.7 & 73.2 & 75.3 & 68.3 & 66.4 & 76.3 & 57.9 & 72.096 \\
\hline 28 & +1 & +1 & -1 & +1 & +1 & 320.3 & 317.8 & 317.8 & 298.2 & 301.6 & 311.8 & 313.5 & 314.4 & 313.223 \\
\hline 29 & -1 & -1 & +1 & +1 & +1 & 84.6 & 76.7 & 89.3 & 76.2 & 79.5 & 87.5 & 77.6 & 77.1 & 83.670 \\
\hline 30 & +1 & -1 & +1 & +1 & +1 & 299.2 & 291.7 & 303.1 & 309.1 & 307.7 & 295.9 & 303.9 & 295.9 & 300.166 \\
\hline 31 & -1 & +1 & +1 & +1 & +1 & 95.9 & 88.9 & 116.6 & 111.9 & 94.1 & 106.7 & 106.3 & 97.8 & 104.093 \\
\hline 32 & +1 & +1 & +1 & +1 & +1 & 337.1 & 350.2 & 359.6 & 364.9 & 350.2 & 337.5 & 350.2 & 365.7 & 346.003 \\
\hline 33 & -1 & 0 & 0 & 0 & 0 & 36.3 & 35.8 & 35.8 & 42.1 & 45.2 & 39.3 & 41.8 & 34.6 & 36.560 \\
\hline 34 & +1 & 0 & 0 & 0 & 0 & 137.1 & 145.6 & 135.2 & 138.1 & 143.2 & 146.5 & 139.5 & 139.5 & 143.964 \\
\hline 35 & 0 & -1 & 0 & 0 & 0 & 63.6 & 71.1 & 72.1 & 74.2 & 65.1 & 76.2 & 67.1 & 74.1 & 69.030 \\
\hline 36 & 0 & +1 & 0 & 0 & 0 & 85.2 & 85.3 & 89.9 & 90.9 & 86.8 & 83.8 & 87.6 & 97.5 & 90.856 \\
\hline 37 & 0 & 0 & -1 & 0 & 0 & 81.2 & 77.1 & 80.3 & 81.2 & 75.3 & 86.2 & 85.1 & 73.2 & 75.234 \\
\hline 38 & 0 & 0 & +1 & 0 & 0 & 59.9 & 74.1 & 81.1 & 80.1 & 77.7 & 81.5 & 82.1 & 74.4 & 82.153 \\
\hline 39 & 0 & 0 & 0 & -1 & 0 & 65.5 & 58.9 & 60.3 & 54.2 & 60.8 & 60.8 & 58.4 & 60.8 & 54.921 \\
\hline 40 & 0 & 0 & 0 & +1 & 0 & 143.7 & 152.6 & 136.6 & 133.8 & 131.7 & 129.1 & 126.7 & 136.5 & 142.453 \\
\hline 41 & 0 & 0 & 0 & 0 & -1 & 78.8 & 87.7 & 87.2 & 89.2 & 85.4 & 87.8 & 84.4 & 86.3 & 81.269 \\
\hline 42 & 0 & 0 & 0 & 0 & +1 & 114.5 & 114.9 & 103.2 & 118.7 & 132.3 & 114.1 & 117.3 & 116.8 & 122.130 \\
\hline 43 & 0 & 0 & 0 & 0 & 0 & 81.1 & 83.1 & 85.2 & 79 & 90.3 & 74 & 82.2 & 82 & 79.009 \\
\hline 44 & 0 & 0 & 0 & 0 & 0 & 80 & 81 & 80.2 & 79.4 & 80.4 & 84.2 & 76.2 & 80.2 & 79.009 \\
\hline
\end{tabular}

For testing the lack of fit in regression, we performed the ANOVA technique for the significance of regression or $R$-square test $(R$-square $=99.18 \%)$. With the ANOVA technique, the regression model is assumed to stay fit as long as the calculated value of the F-ratio of the developed model does not exceed the standard tabulated value of F-ratio for a desired confidence level (Table 4). 
Table 4. Testing lack of fit and analysis of regression equation

\begin{tabular}{|l|c|c|c|c|c|}
\hline \multicolumn{1}{|c|}{ Term. } & Coef. & SE Coef. & T - value & P - value & VIF \\
\hline Constant & 79.009 & 0.898 & 87.95 & 0.000 & \\
\hline$S_{z}$ & 53.702 & 0.444 & 120.84 & 0.000 & 1.00 \\
\hline$\rho$ & 10.913 & 0.444 & 24.56 & 0.000 & 1.00 \\
\hline$\gamma$ & 3.460 & 0.444 & 7.78 & 0.000 & 1.00 \\
\hline$\psi_{C}$ & 43.766 & 0.444 & 98.48 & 0.000 & 1.00 \\
\hline$\psi$ & 20.431 & 0.444 & 45.97 & 0.000 & 1.00 \\
\hline$S_{z}{ }^{*} S_{z}$ & 11.25 & 1.65 & 6.81 & 0.000 & 3.14 \\
\hline$\rho^{*} \rho$ & 0.93 & 1.65 & 0.57 & 0.572 & 3.14 \\
\hline$\gamma^{*} \gamma$ & -0.32 & 1.65 & -0.19 & 0.849 & 3.14 \\
\hline$\psi_{C} \psi_{C}$ & 19.68 & 1.65 & 11.91 & 0.000 & 3.14 \\
\hline$\psi^{*} \psi$ & 22.69 & 1.65 & 13.73 & 0.000 & 3.14 \\
\hline$S_{z}{ }^{*} \rho$ & 6.354 & 0.458 & 13.87 & 0.000 & 1.00 \\
\hline$S_{z}{ }^{*} \gamma$ & 0.196 & 0.458 & 0.43 & 0.669 & 1.00 \\
\hline$S_{z} \psi_{C}$ & 34.469 & 0.458 & 75.25 & 0.000 & 1.00 \\
\hline$S_{z} \psi^{*}$ & 26.235 & 0.458 & 57.27 & 0.000 & 1.00 \\
\hline$\rho^{*} \gamma$ & 3.818 & 0.458 & 8.34 & 0.000 & 1.00 \\
\hline$\rho^{*} \psi_{C}$ & 6.161 & 0.458 & 13.45 & 0.000 & 1.00 \\
\hline$\rho^{*} \psi$ & -4.327 & 0.458 & -9.45 & 0.000 & 1.00 \\
\hline$\gamma^{*} \psi_{C}$ & -3.697 & 0.458 & -8.07 & 0.000 & 1.00 \\
\hline$\gamma^{*} \psi$ & 12.614 & 0.458 & 27.54 & 0.000 & 1.00 \\
\hline$\psi_{C} * \psi$ & -1.338 & 0.458 & -2.92 & 0.004 & 1.00 \\
\hline & & & & &
\end{tabular}

In the case of $\psi_{C}=\psi=0, \gamma=12^{\circ}$ and the machining roughness $\mathrm{R}_{\mathrm{z}} \leq 70 \mu \mathrm{m}$, we have a graph of surface plot and contour lines as shown in Fig. 6.

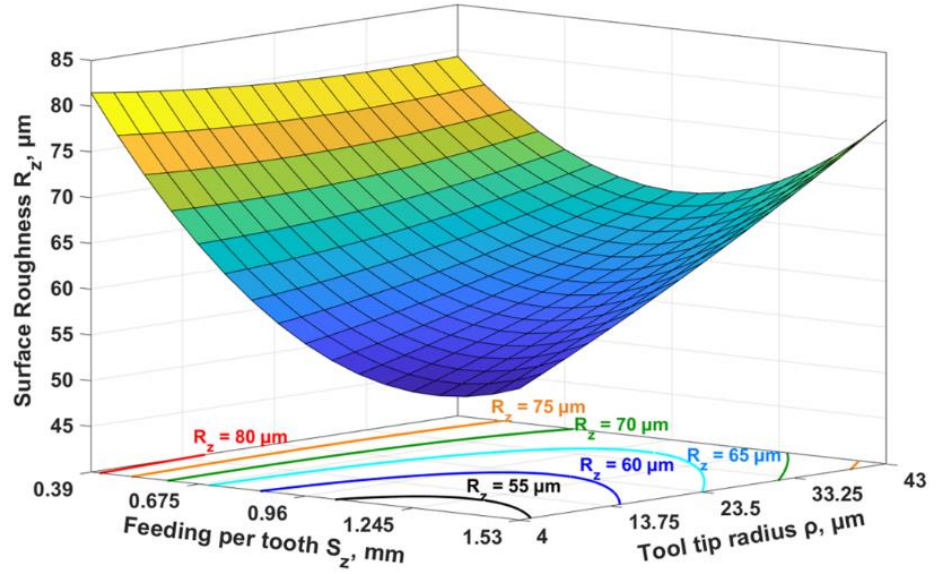

Fig. 6. Plot of surface roughness region in the case of $\psi_{C}=\psi=0$ and $\gamma=12^{\circ}$

\subsection{OPTIMAL CALCULATION RESULTS}

Problem 1: Minimum cutting power $P$ and roughness constraint $R_{z} \leq 70 \mu \mathrm{m}$.

With known values of $D=180 \mathrm{~mm}, h=2 \mathrm{~mm}, n=6000 \mathrm{rpm}, z=4, b=200 \mathrm{~mm}$, in the case of the rake angle $\gamma=12^{\circ}$, according to the Kuhn-Tucker conditions in Formula 22, to find the optimal solution, we need to find the solution for the following system of equations: 


$$
\left\{\begin{array}{c}
\frac{\partial P}{\partial S_{z}}+u_{1} \frac{\partial h_{1}}{\partial S_{z}}+u_{2} \frac{\partial h_{2}}{\partial S_{z}}+u_{3} \frac{\partial h_{3}}{\partial S_{z}}=0 \\
\frac{\partial P}{\partial \rho}+u_{1} \frac{\partial h_{1}}{\partial \rho}+u_{2} \frac{\partial h_{2}}{\partial \rho}+u_{3} \frac{\partial h_{3}}{\partial \rho}=0 \\
u_{1} h_{1}=u_{1}\left(70-R_{z}\right)=0 \\
u_{2} h_{2}=u_{2}(\rho-4)=0 \\
u_{3} h_{3}=u_{3}(43-\rho)=0
\end{array}\right.
$$

After solving and removing the imaginary solutions, we obtain the accepted solutions and regions as shown in Fig. 7. Considering the planning region $0.39 \mathrm{~mm} \leq S_{z} \leq 1.53 \mathrm{~mm}$, in Fig. 7, only 3 solutions: $S_{z}=0.5942 \mathrm{~mm}, S_{z}=0.6965 \mathrm{~mm}$ and $S_{z}=1.2659 \mathrm{~mm}$ are satisfied. However, to ensure the tool life and then $4 \mu \mathrm{m} \leq \rho \leq 43 \mu \mathrm{m}, S_{z}$ changes from $0.6965 \mathrm{~mm}$ to $1.2659 \mathrm{~mm}$ as the curve $\rho=43 \mu \mathrm{m}$ in Fig. 8 .

Problem 2: The highest productivity with roughness constraint $R_{z} \leq 70 \mu \mathrm{m}$ and cutting power $P \leq P_{\text {req }}$

With parameters the same as those in problem 1 and $P_{\text {req }}=13 \mathrm{~kW}$, according to KuhnTucker conditions in Formula 22, we have a system of equations:

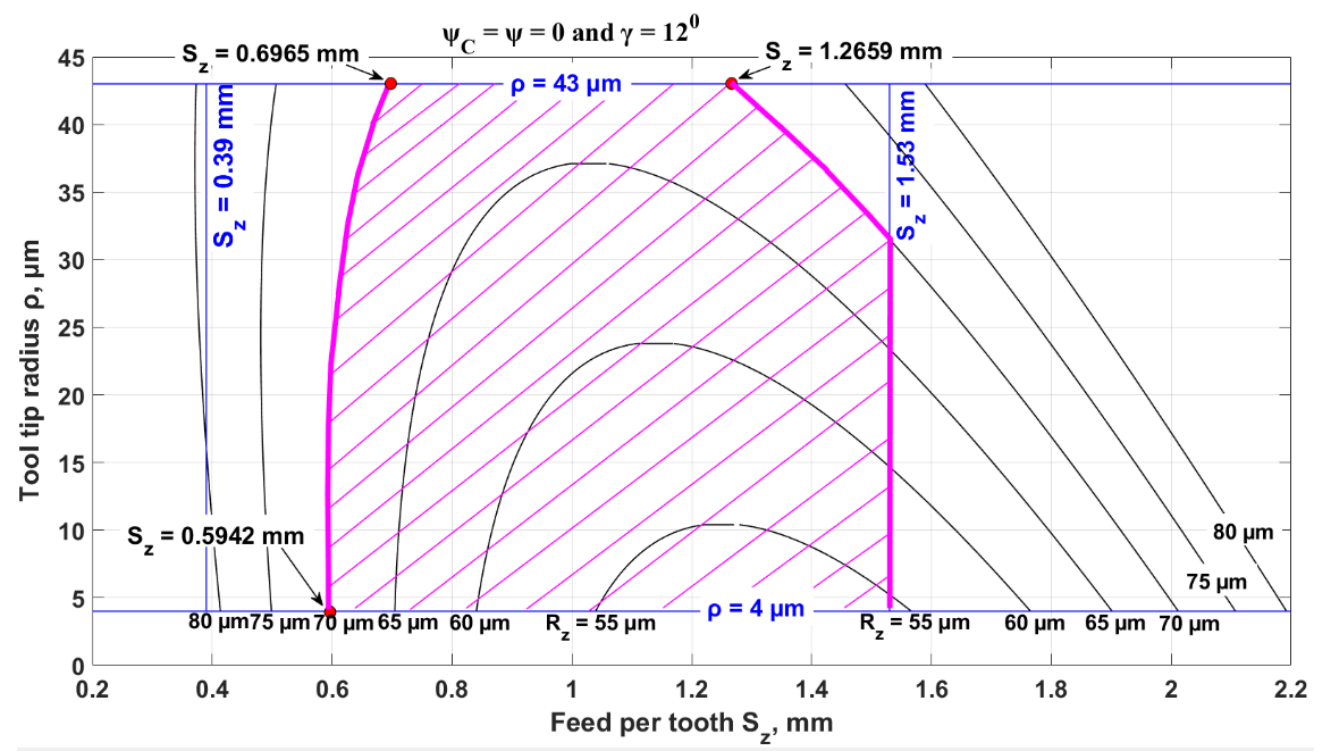

Fig. 7. Area of solution points of problem 1 with constraint $R_{z} \leq 70 \mu \mathrm{m}$

$$
\left\{\begin{array}{c}
\frac{\partial u}{\partial S_{z}}+u_{1} \frac{\partial h_{1}}{\partial S_{z}}+u_{2} \frac{\partial h_{2}}{\partial S_{z}}+u_{3} \frac{\partial h_{3}}{\partial S_{z}}+u_{4} \frac{\partial h_{4}}{\partial S_{z}}=0 \\
\frac{\partial u}{\partial \rho}+u_{1} \frac{\partial h_{1}}{\partial \rho}+u_{2} \frac{\partial h_{2}}{\partial \rho}+u_{3} \frac{\partial h_{3}}{\partial \rho}+u_{4} \frac{\partial h_{4}}{\partial \rho}=0 \\
u_{1}\left(P_{m}-P\right)=0 \\
u_{2}\left(70-R_{z}\right)=0 \\
u_{3}(\rho-4)=0 \\
u_{4}(43-\rho)=0
\end{array}\right.
$$

After solving and removing the imaginary solutions, we get the solution and the optimal parameter region as shown in Fig. 9. 


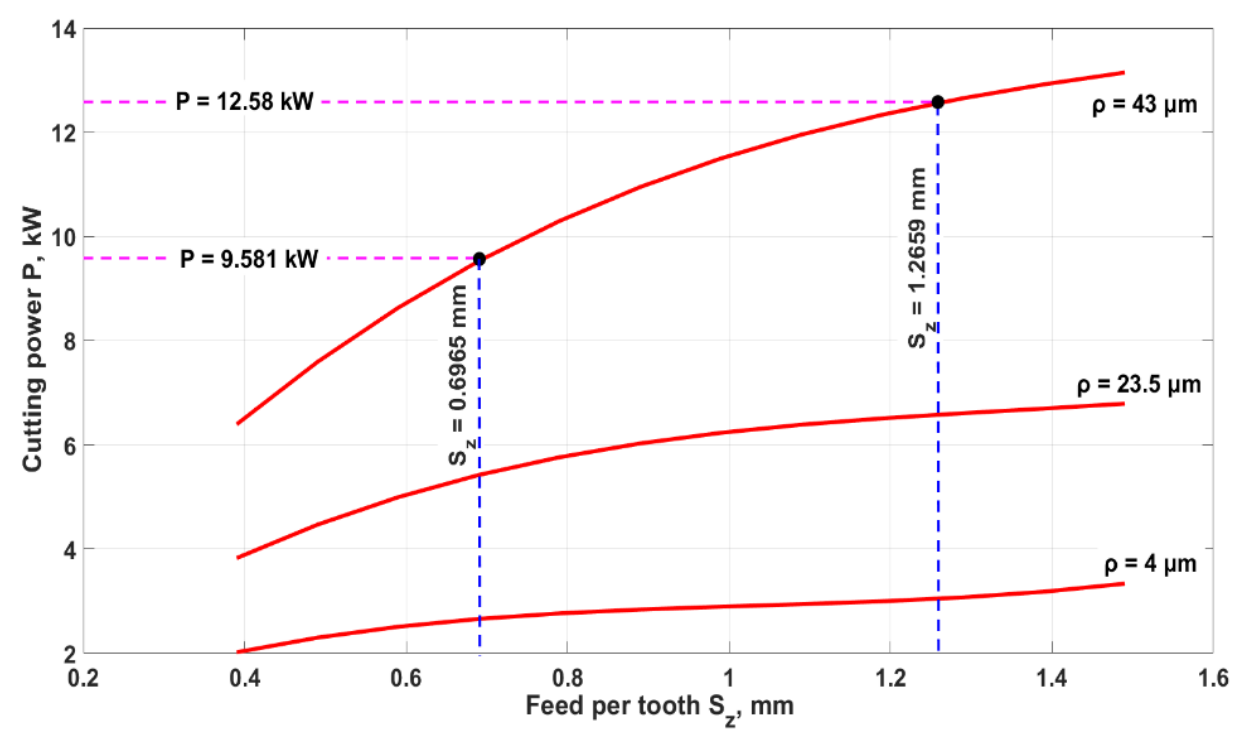

Fig. 8. Optimal power region $(9.581 \ldots 12.58 \mathrm{~kW})$ of problem 1

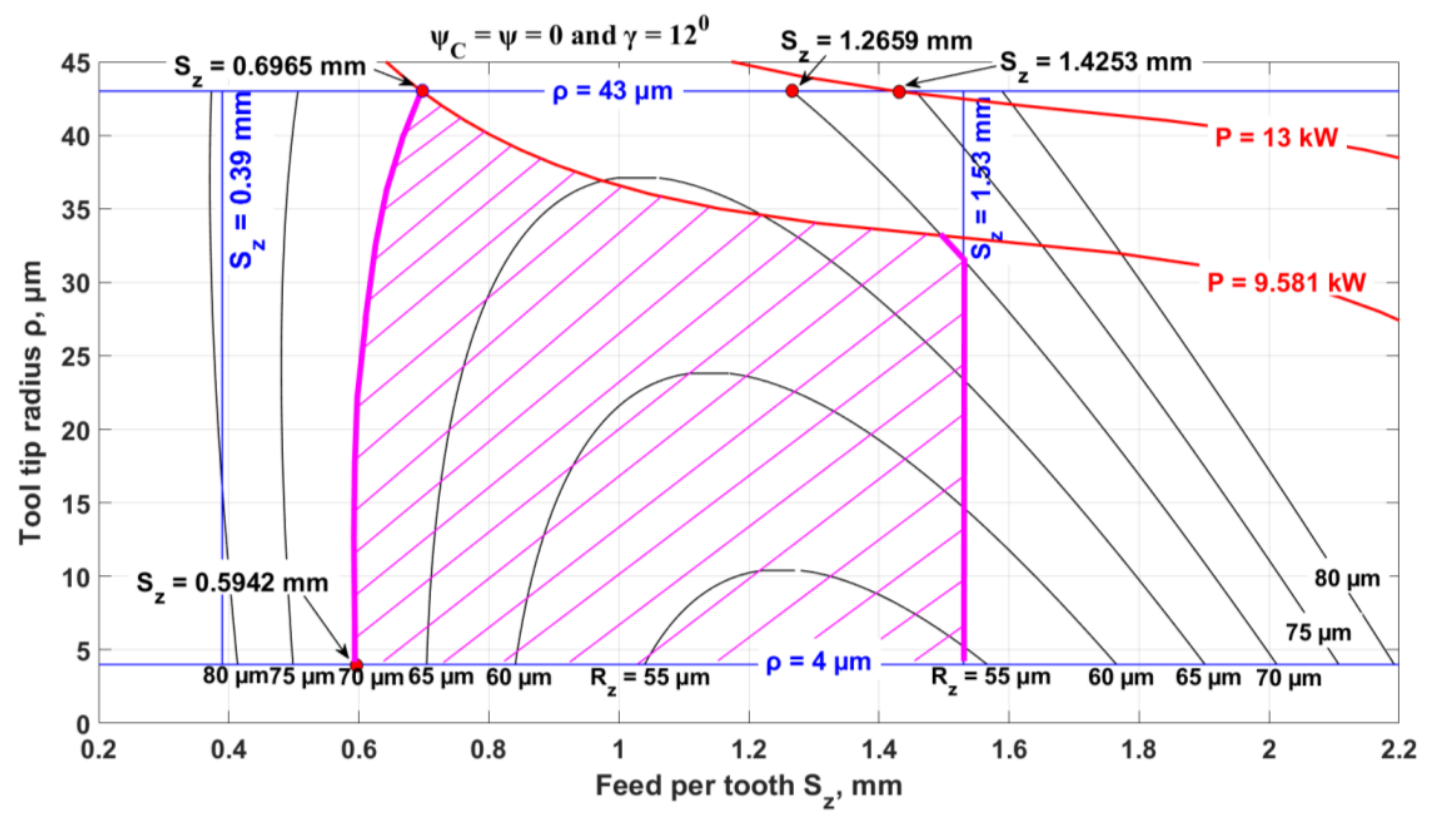

Fig. 9. Optimal region of problem 2 with constraint $P_{\text {req }}=9.581 \mathrm{~kW}$

Problem 3: The lowest processing cost with constraint $R_{\mathrm{z}} \leq 70 \mu \mathrm{m}$, low power loss and high productivity.

With known values of $n=6000 \mathrm{rpm}, z=6, b=200 \mathrm{~mm}, \rho_{0}=4 \mu \mathrm{m}, \psi_{C}=\psi=0, \gamma=12^{0}$. The value of feeding speed ranges from $14.04 \mathrm{~m} / \mathrm{min}$ to $55.08 \mathrm{~m} / \mathrm{min}$ (according to the formula $u=n \cdot z \cdot S_{z}$ corresponding to $S_{z}$ varying from $0.39 \mathrm{~mm}$ to $1.53 \mathrm{~mm}$ ). The graph of the cutting time $\tau_{0}$ is a curve according to Formula 28, reaching the value $\tau_{0}$ at $\rho=43 \mu \mathrm{m}$ and constraints shown in Fig. 10.

Considering the condition of minimum cutting power: When the curve $\tau=19800 \mathrm{~min}$ at the $R_{z} \leq 70 \mu \mathrm{m}$ section, the feed per tooth will change in the range of $0.645 \mathrm{~mm} \leq S_{z} \leq 1.2659$ $\mathrm{mm}$ and tool tip radius $\rho$ will change in the range of $33.5 \mu \mathrm{m} \leq \rho \leq 43 \mu \mathrm{m}$ (line 1 in Fig. 10): 
- Section 1: In the region of $4 \mu \mathrm{m} \leq \rho \leq 33.5 \mu \mathrm{m}$, the ideal machining line will run in a straight line at the same value of $S_{z}=0.645 \mathrm{~mm}$. Then the cutting time $\tau_{0}$ will change continuously in the interval of $0 \mathrm{~min} \leq \tau_{0} \leq 19800 \mathrm{~min}$.

- Section 2: In the region of $33.5 \mu \mathrm{m} \leq \rho \leq 43 \mu \mathrm{m}$, the ideal machining path will follow the line $\tau=19800 \mathrm{~min}$.

- Considering the condition of the highest productivity: The greater the machining productivity, the larger the $S_{z}$ value (because the feeding speed $\mathrm{u}$ is directly proportional to the feed per tooth $S_{z}$ ). When combined with the minimum cutting time $\tau_{0}(\tau=19800 \mathrm{~min})$ and roughness $R_{z} \leq 70 \mu \mathrm{m}$ constraint, the best machining parameter in this problem is line 2 as shown in Fig. 10.

- Line 2: In this case, the productivity will be optimal, the $S_{z}$ value must be changed continuously to ensure that $R_{z} \leq 70 \mu \mathrm{m}$. In the region of $31.51 \mu \mathrm{m} \leq \rho \leq 43 \mu \mathrm{m}$, the ideal machining path will follow a curve close to the $\mathrm{R}_{\mathrm{z}}=70 \mu \mathrm{m}$ region; and in the region $4 \mu \mathrm{m} \leq \rho \leq 31.51 \mu \mathrm{m}$, the ideal machining path will be machined with the same feed per tooth value $S_{z}=1.53 \mathrm{~mm}$.

- In addition, we can choose the parameters in the allowable region (hatch area) while ensuring the roughness is within the allowable range $R_{z} \leq 70 \mu \mathrm{m}$, power $P \leq 13 \mathrm{~kW}$ and lower than the motor power. Then, the larger $S_{z}$, the higher productivity.

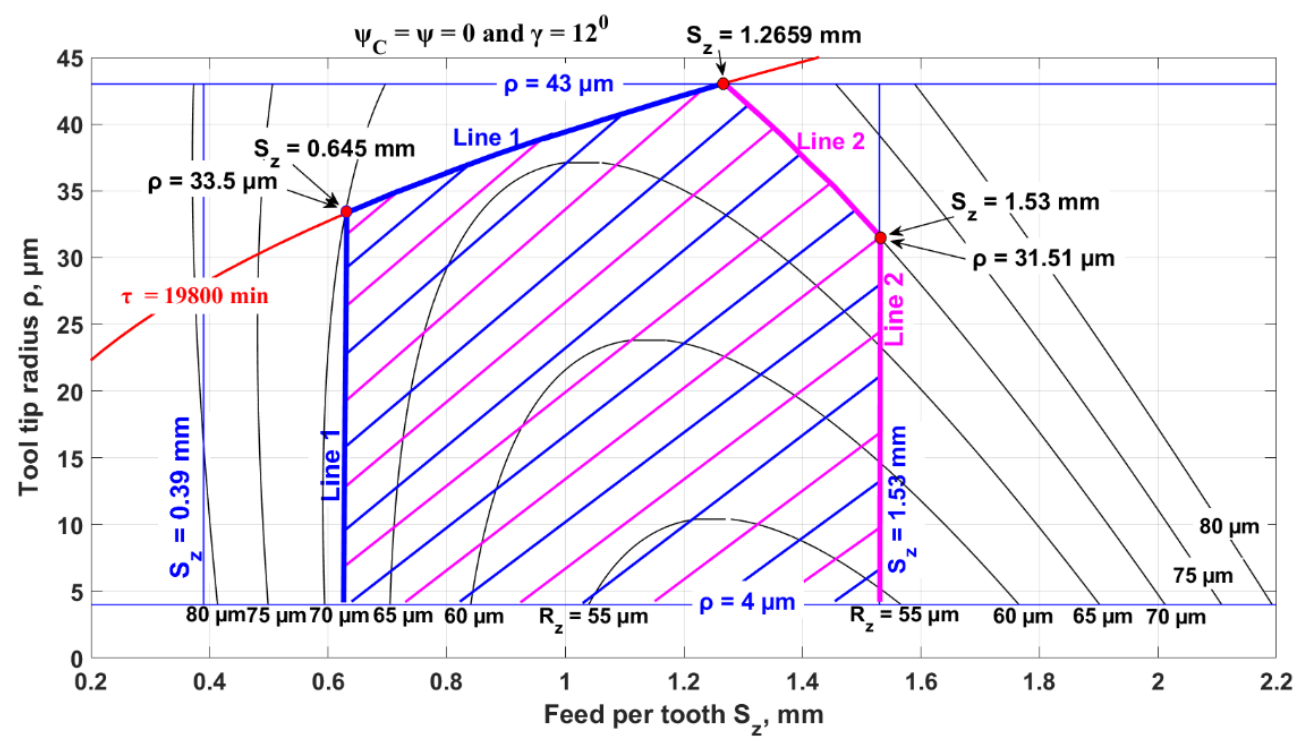

Fig. 10. Ideal machining path for minimum cutting power or highest productivity of problem 3

\section{CONCLUSIONS}

The paper presents issues related to theoretical and experimental bases when milling wood. The theoretical part presents the basic content of surface shaping when milling to shape wood, determining chip thickness, cutting length, and undulating height when milling tropical wood materials. The relevant experimental part uses the response surface methods to determine the surface roughness $R_{z}$ when machining tropical wood, which depends on many 
factors: feed per tooth $S_{z}$, tool tip radius $\rho$, rake angle $\gamma$, grain deviation angle $\psi_{C}$, blade inclination angle $\psi$. From that, it is possible to determine the region of geometric parameters and work when milling wood so that the roughness is within the given range $R_{z} \leq 70 \mu \mathrm{m}$ corresponding to the semi-finished milling method.

The authors used the constrained nonlinear optimization problem solving method to find a reasonable cutting mode that ensures the surface roughness in the given range, minimum power and the highest productivity for tropical wood materials - chukrasia, such as:

- The minimum cutting power $P$ with the roughness constraint $R_{z} \leq 70 \mu \mathrm{m}$, the range of values of parameters such as the feed per tooth $S_{z}$ and tool tip radius $\rho$, as shown in Fig. 7 and 9.

- The highest productivity with constraint $R_{z} \leq 70 \mu \mathrm{m}$ and power $P \leq P_{\text {req: }}$ define the region of parameters as feed per tooth $S_{z}$ and tool tip radius $\rho$ with required cutting power $P_{\text {req }}=9.581 \mathrm{~kW}$ as Fig. 10 .

- The optimal machining path for the problem of determining the minimum cost is the basis for adjusting the feeding speed $\mathrm{u}$ depending on time $t$. It supports the process of controlling wood milling machines or woodworking CNC machines by milling method.

The content of the paper provides data to design the wood milling machines and cutting tools, especially woodworking CNC machines, with the target of yielding the highest productivity and the least energy consumption, yet still ensuring the desired surface quality.

\section{ACKNOWLEDGMENTS}

We acknowledge the support of time and facilities from Ho Chi Minh City University of Technology (HCMUT), VNUHCM for this study.

\section{REFERENCES}

[1] KILIC M., HIZIROGLU S., BURDURLU E., 2005, Effect of Machining on Surface Roughness of Wood, Building and Environment, 41, 1074-1078.

[2] WILKOWSKI J., ROUSEK M., SVOBODA E., KOPECKY Z., CZARNIAK P., 2013, Analysis of the Influence of Cutting Parameters on Surface Roughness of Milled Wood Based on Taguchi Techniques, Forestry and Wood Technology, 84, 321-325.

[3] PEREIRA K.M., GARCIA R.A., NASCIMENTO A.M., 2018, Surface Roughness of Amazonian Woods, Scientia Forestalis, 119, 347-356.

[4] WILKOWSKI J., CZARNIAK P., GÓRSKI J., JABLONSKI M., PACEK P., PODZIEWSKI P., SZYMANOWSKI K., SZYMONA K., 2015, Influence of Cutting Parameters on Surface Roughness of MDF Board After Milling and Sanding, Forestry and Wood Technology, 92, 4-476.

[5] LOC N.H., 1992, Researching Reasonable Tropical Wood Cutting by Milling Method, Ph.D Thesis, Belarusian National Technical University, Minsk.

[6] KROL O., 2020, Selection of Machine Tools Optimal Cutting Modes for Designers, Prof. Marin Drinov Publishing House of Bulgarian Academy of Sciences, SOFIA.

[7] KOC K.H., ERDINLER E.S., HAZIR E. et al, 2017, Effect of CNC Application Parameters on Wooden Surface Quality, Measurement, 107, 12-18.

[8] ISLEYAN U.K., KARAMANOGLU M., 2019, The Influence of Machining Parameters on Surface Roughness of MDF in Milling Operation, BioResources, 14, 3266-3277. 
[9] SOGUTLU C., 2017, Determination of the Effect of Surface Roughness on the Bonding Strength of Wooden Materials, BioResources, 12, 1417-1429.

[10] KILIC M., 2015, Effects of Machining Methods on the Surface Roughness Values of Pinus Nigra Arnold Wood, BioResources, 10, 5554-5562.

[11] ZHONG Z.W., 2021, Surface Roughness of Machined Wood and Advanced Engineering Materials and Its Prediction: A review, Advances in Mechanical Engineering, 13, 1-19.

[12] KETURAKIS G., JUODEIKIENE I., 2007, Investigation of Milled Wood Surface Roughness, Materials Science, $13,47-51$.

[13] DOBRZYNSKI., M., ORLOWSKI K.A. I BISKUP M., 2019, Comparison of Surface Quality and Tool- Life of Glulam Window Elements after Planing, Drvna industrija, 70, 7-18.

[14] NEMLI G., AKBULUT T., ZEKOVIÇ E., 2007, Effects of Some Sanding Factors on the Surface Roughness of Particleboard, Silva Fennica, 41/2, https://doi.org/10.14214/sf.302.

[15] SANDAK J., ORLOWSKI K.A., SANDAK A., CHUCHALA D.I., TAUBE P., 2020, On-Line Measurement of Wood Surface Smoothness, Drvna industrija, 71, 193-200.

[16] FISHER H., 1905, Die Werkzeugmaschine, J. Springer, Berlin.

[17] ROZENBLIT G.C., 1937, About the Direction of Feed When Milling Wood, Machines and Tools, 16.

[18] SALOMON C., 1918, Zur Theorie der Fräs Vorganges, Z.d.VDI No., 15.

[19] MARTELLOTTI M.E., 1941, An Analysis of the Milling Process, Trans. ASME, 677-700.

[20] LOC N.H., HUNG T.Q., 2021, Study the Surface and Chip Formation of Wood Materials by Milling Method, Materials Science Forum, 1047, 74-81.

[21] ELSISY M.A., HAMMAD D.A., EL-SHORBAGY M.A., 2020, Solving Interval Quadratic Programming Problems by Using the Numerical Method and Swarm Algorithms, Complexity, Article ID 6105952,| https://doi.org/10.1155/2020/6105952.

[22] STEFANOVA M., MINEVICH O., BAKLANOV S., PETUKHOVA M., LUPULEAC S., GRIGOREV B., KOKKOLARAS M., 2020, Convex Optimization Techniques in Compliant Assembly Simulation, Optimization and Engineering, 21, 1665-1690.

[23] WADOOD A., KIM C.H., KHURSHIAD T., FARKOUSH S.G., RHEE S.B., 2018, Application of a Continuous Particle Swarm Optimization (CPSO) for the Optimal Coordination of Overcurrent Relays Considering a Penalty Method, Energies, 11, 1-20.

[24] SABERMAHANI S., ORDOKHANI Y., YOUSEFI S.A., 2019, Fractional-order Lagrange polynomials: An Application for Solving Delay Fractional Optimal Control Problems, Transactions of the Institute of Measurement and Control, 41, 2997-3010.

[25] SUMIN M.I., 2012, On the Stable Sequential Kuhn-Tucker Theorem and Its Applications, Applied Mathematics, 3, 1334-1350.

[26] KHORASANI A., SYAZDI M.R., 2017, Development of a Dynamic Surface Roughness Monitoring System Based on Artificial Neural Networks (ANN) in Milling Operation, The International Journal Advanced Manufacturing Technology, 93, 141-151.

[27] HAZIR E., OZCAN T., 2019, Response Surface Methodology Integrated with Desirability Function and Genetic Algorithm Approach for the Optimization of CNC Machining Parameters, Arabian Journal for Science Engineering, 44, 2795-2809.

[28] GHOSH G., MANDAL P., MONDAL S.C., 2019, Modeling and Optimization of Surface Roughness in Keyway Milling Using ANN, Genetic Algorithm, and Particle Swarm Optimization, The International Journal of Advanced Manufacturing Technology, 100, 1223-1242.

[29] LOC N.H., Van THUY T.., 2022, Applying FCCD Method in Studying the Cutting Power of the Wood Milling Machine, Solid State Phenomena, 330, 25-31.

[30] NGUYEN T.B, 2003, Optimizing the Cutting Process, Education Publisher.

[31] LOC N.H., 2021, Experimental Study of Tool Wear when Milling Tropical Wood with Various Tool Materials, Key Engineering Materials.

[32] LOC N.H., HUNG N.P., 2021, Utilizing Response Surface Methods Designs for Optimization of Technological Parameters on the Vibration Amplitude of CNC Router Spindle, ASEAN Engineering Journal, 11, 34-44.

[33] HAZIR E., ERDINLER E.S., KOC K.H., 2018, Optimization of CNC Cutting Parameters Using Design of Experiment (DOE) and Desirability Function, Journal of Forestry Research, 29, 1423-1434. 